\title{
Comparative Study of Juvenile Probation System between Japan and the United Kingdom
}

\author{
Miho KOSUGE ${ }^{1}$ ( Member ) \\ ( ${ }^{1}$ Kanto Region Psychologist Association ) \\ Key Words: Juvenile Probation, Japan, United Kingdom
}

\section{Purpose}

According to the United Nation definition in 1951 [1], "Probation is a method of dealing with specifically selected offenders and ... consists of the conditional suspension of punishment while the offender is placed under personal supervision and is given guidance or treatment".

This definition is universal. However probation systems vary widely depending on nations. The author interested in the fact and considers the variation as reflections of cultural background of sense of value. Based on such way of thinking, quintessential features and plausible problems in nations are discussed several standpoints including quintessential cultural and quantitative aspects.

\section{Discussion of Cultural Background}

Japanese Probation System

According to Kawai [2], the Japanese tradition often focuses on the aesthetic value much more than ethical judgment comparing Westerners. If so, voluntary base, or with no salary, probation system [3] is understandable in a degree. Kawai also emphasizes that Japanese often think much of balancing of plural principles more than insist sole principle. It might well explain the fact of volunteer probation officers in Japan have engaged in other volunteer activities as shown in Fig.1 (modified from [4]). As to the Japanese word "Hogo-shi", the former part means "protection", which may suggests the sense of value of maternal principle underling the system.

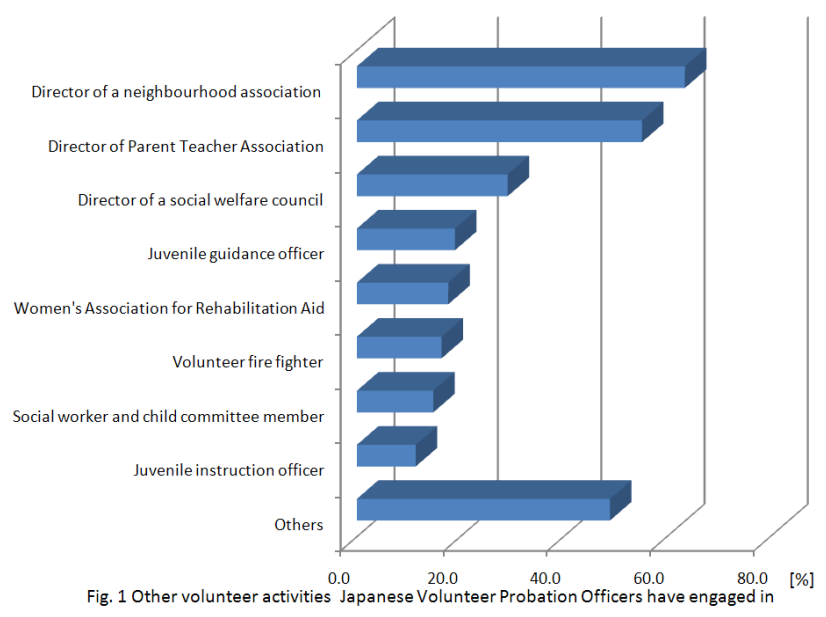

The United Kingdom Probation System

On the contrary, Westerners, for example, the UK seems to adopt a probation system based on paternal principle [2] which stresses clear discrimination based on a decisive distinction on a standard [6]. Based on such an obvious concept, ethical judgment is dominant. The word origin of Probation is from late Latin "proba", or proof, (in medieval Latin examination), from Latin "probare", to test. This fact reminds us of rather clear observation for reasonable decision based on paternal principle

Possible long term issues in Japanese Probation System Generally speaking, where maternal principle is dominant, the balancing principles [6] and endurance power may be much more valued. It may be desirable for Volunteer probation officers to keep in mind this tendency and consequent advantage and disadvantages from such tendency.

Possible long term issues in the UK Probation System Generally speaking, where paternal principle prevails, there may be a disadvantage to put too much emphasis on single principle. A certain kind of compensative function, which was originally expected for the probation system, is difficult to be realized.

Discussion of Statistical Features:

Relatively low crime rate in Japan, comparing to the Western nations [6], may be explained by the inclusion characteristics and networking features by strong affection of maternal principle in the culture which Volunteer Probation Officer System. On one hand, it has been pointed out the urgent need to recruit young officers [4]. On the other hand, the percentage of female volunteers desirably increased constantly. The percentage grew from about $7 \%$ of 1953 to $25 \%$ of 2004 , now representing one out of four [4]. In order to keep and horn quintessential good qualities of our nations voluntary probation officer system into more universal values, the author plans continue to study the UK probation system with plenty of paternal principle by exchange views and opinions of researchers and practitioners in the field as well.

Bibliography

[1] The United Nations Activities and International Trends in Probation, Manuel López-Rey, The Howard Journal of Criminal Justice Volume 9, Issue 4, pages 346-353, 1957

[2] Kawai H., Buddhism and the art of psychotherapy, $2^{\text {nd }}$ printing, Texas Press, 2008

[3] Volunteer Probation Officers Law, Japan (Act No. 204, 1950)

[4] White Paper on crime, Ministry of the Justice, 2004

[5] Kawai H., Dreams, Myths and Fairly Tails in Japan, Daimon Press, 1995

[6] Great Britain: National Probation Service, Stationery Office Books, 2007 